\title{
Entrevista
}

\section{Conversando com Carl Leukefeld}

Neste número, temos a satisfação de ter como entrevistado o Dr. Carl Leukefeld, Ph.D., assistente social, professor de Ciências do Comportamento, atuando nos Departamentos de Psiquiatria e Assistência social da Universidade de Kentucky. O Dr. Leukefeld é também o diretor do Center on Drug and Alcohol Resear$c h$, onde é responsável por uma equipe de 125 profissionais e por um orçamento anual de cerca de sete milhões de dólares. Sob sua direção são desenvolvidas pesquisas, atividades educacionais e programas clínicos dentro e fora da Universidade, inclusive em outros países. É doutor pela Universidade de Michigan e professor da Universidade de Kentucky, com inúmeros artigos e livros publicados. Por sua prolífica atuação na área social, recebeu da National Association of Social Workers Foundation (NASWF), o prêmio Lifetime Achievement Award 2003. O Dr. Leukefeld abriu espaço em sua agenda quando esteve em Porto Alegre como consultor do projeto Risk Reduction and HIV prevention among drug injectors and their sex partners, desenvolvido pelo Centro de Pesquisa em Álcool e Drogas (UFRGS) em parceria com a Universidade de Dellaware. A Revista de Psiquiatria conversou com o Dr. Leukefeld sobre algumas de suas principais áreas de atuação: o uso de drogas em ambientes rurais, as comunidades terapêuticas para usuários de drogas em presídios e a violência contra a muIher relacionada ao uso de drogas. Esta entrevista foi concedida a Antônio Marques da Rosa e Jair Knijnik, do Conselho Editorial. Participa- ram como convidadas Jane Chachamovich, assistente social, e Elisabeth Meyer, pesquisadora assistente do projeto acima mencionado.

Revista de Psiquiatria (RP) - Inicialmente, gostaríamos de agradecer-Ihe por ter encontrado um espaço na sua agenda para esse encontro. Também desejamos congratulá-lo pelo Lifetime Achievement Ward que o senhor recebeu nesse ano. Eu gostaria de iniciar a nossa entrevista com um resumo de sua biografia, quando começou seu interesse pelo trabalho social e, mais especificamente, pela saúde mental e como tudo chegou ao presente prêmio.

Carl Leukefeld (CL) - Acredito que minha jornada em direção ao serviço social e à saúde mental iniciou no segundo grau, quando eu tentava entender as pessoas, muitos anos atrás. 0 interesse surgiu também de fontes políticas em meu país, devido à guerra no Vietnam. Eu freqüentava uma pequena escola e me interessava por grupos, pela dinâmica de grupos. A guerra do Vietnam começava, e eu fui para a faculdade de serviço social. Graduei-me pela universidade de Michigan como assistente social e fui designado para o serviço social público como oficial comissionado. Lá fiquei por vinte e três anos, no National Institutes of Health, no National Institute of Mental Health e no National Institute on Drug Abuse. Sempre me interessei pela saúde mental, trabalhando com psicólogos, clínicos, psiquiatras, assistentes sociais e pesquisadores. Interessei-me então 
pelo denominador de tudo isso, como numa equação, pelas taxas por cem mil pessoas. Interessei-me pelo que chamamos a caixa preta do tratamento, como tudo isso funciona. Minha carreira é centrada, basicamente, em como entender uma intervenção. Fui encaminhado para um doutorado quando trabalhava, por três anos, no escritório do diretor do National Institute of Mental Health. Concluí o doutorado, sempre interessado por usuários de drogas e de que maneira modificar esse comportamento.

$\mathrm{RP}$ - O senhor trabalhou com veteranos da guerra do Vietnam nesse campo?

$\mathrm{CL}$ - Não. Conheci alguns, mas não trabaIhei com eles. A maior parte do meu trabalho clínico foi muito, muito focada em usuários de drogas. Minha primeira visão disso foi em Lexington, no estado de Kentucky, onde estou agora e onde temos o primeiro hospital para usuários de drogas dos Estados Unidos, que iniciou em 1935. Alguns dos pacientes eram veteranos. Parece que iniciei ontem, mas foi há 35 anos...

$\mathrm{RP}-\dot{E}$ onde o senhor trabalha atualmente com os usuários de drogas?

CL - Sim, como professor de ciências do comportamento em psiquiatria e serviço social, focalizando na mudança de comportamento dos usuários de drogas. Temos uma certa quantidade de diferentes verbas do National Institute of Mental Health (NIMH) e algumas são destinadas a mudar o comportamento dos usuários de drogas em relação ao HIV. Temos diversos projetos nesse sentido.

$\mathrm{RP}$ - Então todos os projetos, tanto aqueles dentro das prisões, quanto os que ajudam mulheres vítimas de violência, são relacionados ao uso de drogas.

$\mathrm{CL}$ - Sim. É a ênfase principal, desde que estamos no Center on Drug and Alcohol Research. A saúde mental é parte disso, mas o foco são os usuários de drogas. No meu país, se tenta entender a diferença entre uso de drogas diferentes do álcool e o uso de álcool. Isso é politicamente dividido em três institutos de nível federal: National Institute of Mental Health (NIMH), National Institute on Drug Abuse (NIDA) e National Institute of Alcohol Abuse and Alcoholism (NIAAA). grande interesse para os nossos leitores, como a psiquiatria forense, $o$ abuso de drogas e $o$ progresso da AIDS e suas conseqüências para a saúde mental.

$$
\mathrm{CL}-\mathrm{Sim} \text {. }
$$

RP - Eu trabalho em um hospital psiquiátrico forense do estado. E temos grandes problemas lá, visto que há uso de drogas, doenças psiquiátricas, crimes e AIDS. Como são nos Estados Unidos os programas quanto ao uso de drogas dentro das prisões?

$\mathrm{CL}$ - A maioria dos programas consiste de comunidades terapêuticas, onde existem estágios de tratamento. Há uma fase introdutória, depois uma fase intermediária, em que o indivíduo se torna mais envolvido com o programa, e um terceiro estágio, em que ele toma parte da liderança da comunidade terapêutica. Isso leva de seis a nove meses. Muitas prisões oferecem esses programas. Em alguns estados, há programas especializados de tratamento, como na Califórnia. Em nosso estado, Kentucky, temos tratamento dentro das prisões. O tratamento faz parte da prisão e, se o indivíduo se comporta bem, ele sairá antes. E fora, como ex-prisioneiro, o individuo pode decidir se quer se envolver no tratamento após sair da prisão. Constatamos que o tratamento na prisão precisa vincular-se ao tratamento fora da prisão, precisa de um acompanhamento. Isso não é diferente de quando eu comecei, nos anos sessenta, quando o presidente John F. Kennedy chamou-o de novo enfoque audacioso (bold new approach) para o tratamento da saúde mental. O paciente sai da prisão para a comunidade e recebe cuidados. Mas a infra-estrutura para a segunda parte não existe em nosso país, por múltiplas razões. Não temos feito um trabaIho suficientemente bom quanto ao HIV nas prisões. Temos programas, todos têm informações sobre o HIV, mas o HIV entre usuários de drogas vem se mantendo em uma curva plana, ele não tem aumentado. Então melhoramos por um lado, mas por outro ainda estamos na mesma.

$\mathrm{RP}$ - Os prisioneiros entram nos programas voluntariamente ou o ingresso é obrigatório? grama.

CL - Eles são obrigados a entrar no pro-

$\mathrm{RP}$ - O senhor pensa que os resultados seriam diferentes em uma ou outra situação? 
$\mathrm{CL}-\mathrm{Na}$ verdade, as taxas são bastante semelhantes em nosso país. Fizemos pesquisas sobre esse assunto durante anos. Pensávamos que quem ingressasse voluntariamente teria desempenho melhor, mas é quase a mesma coisa. E existem diversos estudos. Há até estudos anteriores que diziam que as pessoas que eram forçadas ao tratamento se saíam meIhor. Mas se perguntarmos, a pessoa dirá que prefere estar voluntariamente no programa.

$\mathrm{RP}$ - O senhor pensa que o contágio com HIV nas prisões americanas ocorre mais pelo uso de drogas ou por relações sexuais?

CL - Eu não sei... Essas coisas estão juntas, a meu ver. O que vocês acham?

RP - Talvez por via sexual, mas temos grande problema com drogas dentro das prisões, aqui. Vocês também têm o problema de entrada de drogas nas cadeias, não?

CL - Temos, mas não falamos sobre isso... Nós fazemos revistas gerais e encontramos drogas. Mas as pessoas não querem falar sobre isso. Há tempos atrás descobrimos que havia drogas nas prisões e que os guardas e funcionários as traziam para dentro, mas não se fala sobre isso...

$\mathrm{RP}$ - Geralmente as drogas entram com a conivência de funcionários.

CL - Há visitas aos sábados e domingos, e muitas pessoas entram, o controle é difícil. Se você fosse um guarda penitenciário, talvez adorasse que houvesse alguma droga na prisão, pois é algo que mantém o comportamento geral em um nível não agressivo. Não gostaria que tivesse quantidades de cocaína, mas gostaria que tivesse morfina, ou heroína...

RP - Não apenas as drogas, mas também o sexo na prisão serve ao objetivo de baixar a ansiedade de estar preso, privado da liberdade.

$$
C L-\operatorname{Sim} \text {, com certeza. }
$$

$\mathrm{RP}$ - O senhor conhece prisões em diferentes países, devido ao seu trabalho?

CL - Sim, da Espanha, Holanda, Colômbia, Panamá, Canadá, Hungria e alguns outros.

$\mathrm{RP}$ - Essa pergunta é pela curiosidade de saber se o sexo e o uso de drogas têm diferen- ças nos diferentes sistemas prisionais.

$\mathrm{CL}-\mathrm{Eu}$ não sei muito porque meu foco não é esse, meu foco é ajudar as pessoas. Meu interesse não é no contrabando de drogas nos presídios. Meu interesse é: as pessoas estão lá, então como posso ajudar? Como é esse ambiente e como posso oferecer um milieu terapêutico? Se vocês têm como certo que na prisão existirão drogas ou outras coisas que não são positivas, então tente oferecer uma comunidade terapêutica na cadeia. Não sei se vocês conhecem uma comunidade terapêutica na prisão. Mas, quando se entra em uma prisão que a possui, em geral você vê uma linha no chão e o que está atrás dessa linha é escuro, sem pintura, enquanto que na frente é tudo claro e colorido. É um ambiente do qual se orgulham, com um milieu terapêutico. Foi com Maxwell Jones (psiquiatra militar que desenvolveu o conceito de comunidade terapêutica na Inglaterra e Estados Unidos para tratar soldados que sofriam da fadiga do combate) que se iniciaram essas áreas psiquiátricas para a meIhora dos pacientes. É um ambiente diferente. E estamos interessados em criar esse tipo de ambiente terapêutico, que também é fisicamente atrativo. É uma abordagem diferente.

$\mathrm{RP}$ - O senhor também trabalha com as famílias dos presos?

$\mathrm{CL}$ - De modo geral, se um homem é preso, ele terá sua esposa visitando-o. Se uma mulher é presa, é o oposto, são quase $80 \%$ contra $10 \%$. A mulher visitará o homem, mas dificilmente o homem a visitará. No nosso país, muitas dessas mulheres terão problemas, porque os homens tentarão ter um relacionamento, e isso trará problemas. Por isso, trabalhar com as famílias é difícil em muitas ocasiões.

$\mathrm{RP}-$ E trabalhar com as famílias na comunidade terapêutica?

$C L$ - Também é difícil. E por quê? Porque muitas famílias estão num processo de negação e o interesse pelo tratamento está relacionado, penso eu, à situação sócio-econômica do indivíduo. E a maioria dessas pessoas é de baixa renda, o que traz uma série de problemas para as famílias, relacionados ao funcionamento, ao comportamento, à maneira como a família interage. E a família não é valorizada e não recebe apoio, em muitos lugares do nosso país.

$\mathrm{RP}-\mathrm{O}$ senhor observa que o comporta- 
mento do usuário de droga muda quando ele retorna para a família? Ele conserva a mudança?

$\mathrm{CL}$ - Algumas vezes. Mas se você acredita que o uso de droga, ou adição à droga, ou dependência à droga, é um transtorno crônico com recaídas - eu não chamo de doença, chamo de transtorno (disorder) -, uma vez que o individuo tenha, ele sempre passará por recaídas, passará por períodos sem usar a droga, depois voltará a usar. E o que nós fazemos é tentar tornar mais longo o período em que não usa; ao mesmo tempo, tentamos fazer o período de uso mais curto. Então, se olharmos para isso como uma carreira, veremos que o que nós fazemos é tentar reduzi-la e fazer com que a pessoa entenda que, por ter usado uma vez, não significa que vai ficar usando para sempre. Esse é o fato mais importante, e a família também precisa compreender. Mas muitas vezes a família não compreende. É um trabalho difícil. Mesmo manter a família vindo às sessões é um trabalho difícil. Quer dizer, lá é o mesmo que aqui, é difícil.

RP - O senhor nos falou sobre as comunidades terapêuticas e fiquei curioso em saber como os indivíduos com personalidade antisocial interagem nessas comunidades, porque é o que temos nas prisões aqui.

$\mathrm{CL}$ - Penso que o problema é selecionar as pessoas envolvidas em uma comunidade terapêutica. Como ela é dirigida por usuários de drogas juntamente com os profissionais, parte da seleção acontece naturalmente. As personalidades realmente anti-sociais, provavelmente, poderiam trabalhar por algum tempo num ambiente assim, mas seriam desligadas depois. Há muito debate sobre o assunto, e esse comportamento é trazido à tona e discutido de forma franca, nada é escondido. A discussão acontece entre seus pares, e eles mesmos o desligam. Também temos comunidades residenciais onde ficam por períodos de tempo menores, sendo que as personalidades antisociais se envolvem mais nessas comunidades. Boa pergunta.

$\mathrm{RP}$ - Essas pessoas têm a característica de não se envolverem.

$\mathrm{CL}-\mathrm{Sim}$, exatamente.

RP - Tenho uma pergunta sobre a violên482 cia contra a mulher e o uso de álcool, que é um assunto que Ihe interessa. No Brasil alguns dados mostram que existe uma coincidência entre violência contra a mulher e abuso de álcool de mais de $30 \%$. Esse dado seria semeIhante nos Estados Unidos?

$\mathrm{CL}$ - Sim, semelhante ou um pouco mais alto. A combinação entre álcool e outras drogas e violência contra mulheres é alta. Se considerarmos não só a violência física, mas também a psicológica, os números serão ainda mais altos. Quando falamos em violência, incluímos também a psicológica, como ameaças, intimidação, não permitir à mulher fazer determinadas coisas, devido à natureza controladora dos homens. E todas essas coisas podem ter um caráter aditivo.

RP - Não é incomum que o casal, tanto o agressor quanto a vítima, façam uso de álcool. Pode haver um conluio inconsciente por parte da vítima, com o uso do álcool para provocar a agressão.

CL - Sim, sim, sem dúvida. Ou o uso da droga para fazer surgir a agressividade. A cocaína é ainda mais relacionada à violência e agressão, em especial se o homem traz a muIher a algo que chamo de relacionamento com a droga. Ele a apresenta à droga, com ou sem fantasias a respeito da droga, e a relação com a droga, então, se torna mais importante que a relação com o homem. Isso ajuda a perpetuar a violência.

RP - O senhor trabalha com mulheres da área rural vítimas da violência: o senhor acredita que a violência doméstica seja diferente em ambientes urbanos e rurais?

CL - Constatamos que o nível de violência é quase o mesmo. Mas o modo como a violência é perpetuada é muito diferente para a muIher rural. Há mais intimidação e isolamento.

$\mathrm{RP}$ - Ela não pode recorrer à ajuda.

$\mathrm{CL}-$ Certo. É como um cobertor, que a mantém isolada. Outro dado que encontramos é que, quando um homem se afasta da família por um período de tempo para realizar algo e a família tenta se estabilizar, no nosso sistema social - e isso está mudando - a mulher é encorajada a trabalhar. Mas na área rural dificilmente há trabalho. Então, dizem à mulher que ela precisa trabalhar, mas, ao mesmo tempo, não há trabalho. Com o homem, acontece que 
ele se afasta com a expectativa de que, no regresso, a casa estará perfeita como antes. Isso também ajuda a perpetuar a violência. Eu coordenei um grupo de mulheres em uma prisão, há tempos atrás. Falávamos sobre a violência que sofrem e sobre como estava a saúde delas. E ali havia uma mulher - nosso grupo era de nove pessoas - que não dizia nada, absolutamente nada. Mas no final ela levantou e disse: "olhem, vejam o que ele me fez". Ela inclinou a cabeça e mostrou uma cicatriz daqui até aqui (da testa até a região occipital). Então disse: "vejam o que ele me fez aqui". E mostrou a perna, que estava quebrada em múltiplos lugares. Ela participava de uma de nossas pesquisas. Ela disse: "não vou voltar para esse homem". Ela era de uma área rural. Fizemos um follow-up. A mulher voltou, e ele fez a mesma coisa. Esse relacionamento era tão importante para essa mulher que ela o manteve, porque numa área rural ela não encontrava outro lugar para ir. Por isso a violência é tão diferente de uma área urbana. Ela precisava voltar para aquele homem. Então, é semelhante na natureza, mas se comporta de uma maneira diferente. $\mathrm{O}$ isolamento, a falta de recursos, a intimidação...

RP - Em alguns casos, a psicodinâmica poderia ser útil, visto que existem motivações inconscientes, tanto da vítima quanto do agressor, que perpetuam esse tipo de relacionamento. Vocês utilizam também alguma abordagem psicodinâmica?

CL - Nós não desenvolvemos um protocolo específico para essa intervenção. Nós tentamos entender o que está acontecendo e então desenvolvemos um protocolo. É o nosso objetivo. Esse é a nossa próxima fase nesse processo. Nos Estados Unidos, muita gente faz nas áreas urbanas o que fazemos nas áreas rurais. Nossas intervenções são mais comportamentais, pois agimos em áreas com muito poucos psiquiatras, psicólogos e assistentes sociais. Utilizamos uma mescla de pessoas que são indígenas ou da própria área. Temos que estimar aquilo que seja transportável e mais fácil de aplicar. E, como vocês sabem, nada é fácil.

$\mathrm{RP}$ - Sim, a intervenção precisa ser comportamental para retirar a mulher desse processo o mais rápido possível, e a psicodinâmica ficaria para um segundo passo. É preciso fazer com que a violência cesse, isso vem antes.

$C L$ - Sim, o que é a parte mais importante.
RP - O nosso estado tem algumas características semelhantes ao seu, pois tem uma vasta área rural, com propriedades afastadas umas das outras, grandes distâncias, isolamento, poucos profissionais em áreas rurais e uma cultura na qual o homem tem muito poder, o "machismo".

$\mathrm{CL}-\mathrm{Sim}$, muito disso, muito mesmo. E lá muitos dos homens saem para beber e, quando voltam para casa, acontece a violência.

$\mathrm{RP}$ - Se entendi bem, vocês fazem uma mescla daquilo que é melhor naquele momento, para aquele grupo especificamente.

CL: Sim, e envolvemos as pessoas no desenvolvimento da intervenção. Esse é o nosso objetivo.

$\mathrm{RP}-\mathrm{O}$ primeiro passo é entender o que está acontecendo e então desenvolvem a intervenção, sem receita pronta. Cada caso tem sua especificidade.

$\mathrm{CL}$ - Isso. Eu estive no Colorado há algumas semanas e lá também havia gente de áreas rurais de Nevada, Novo México, Arizona, Dakota do Norte e Dakota do Sul. Eles estavam conversando sobre terapia em áreas rurais, como realizar isso. Meu grupo tinha desenvolvido um programa desses durante quatro anos e eles disseram: "bem, poderíamos usar isso!". Eu disse que não se podia afirmar que aquilo seria bom para todo mundo, era preciso entender melhor, as culturas são muito diferentes, muito diferentes...

$\mathrm{RP}$ - O senhor é diretor do Center on Drug and Alcohol Research, que tem um orçamento anual de sete milhões de dólares. Em um país como o Brasil, com orçamentos muito menores, como é possível desenvolver programas efetivos, e quais seriam as prioridades?

$\mathrm{CL}$ - Todos os sete milhões de dólares que temos são doações. Nós nos concentramos no trabalho com mulheres, temos muitos trabalhos nessa área. Mulheres usuárias de substâncias, por exemplo. Cerca de três milhões de dólares são dirigidos para esse trabalho focado nas mulheres. É dinheiro doado pelo estado, é uma verba federal. Então, para nós, as mulheres são uma prioridade. Sempre foi para mim. Também ajudamos as mulheres a obter terapias específicas para elas. No nosso país, há terapias desenvolvidas para homens das quais as 
mulheres participam. Estamos tentando desenvolver terapias para as mulheres, é uma grande prioridade. Também estamos focados nas áreas rurais, pelas quais há pouca gente nos Estados Unidos que se interessa, talvez uns quatro ou cinco centros de estudo. Essas seriam as duas maiores prioridades. E nesse contexto há a Justiça Criminal. Fazemos muito dentro das prisões, tentando entender o que acontece lá dentro. Também trabalhamos muito com HIV. Então, quais seriam as prioridades, para que lado ir? Acho que a resposta é desenvolver intervenções breves, bem focadas, que ajudem as pessoas a se moverem dentro de seu ciclo de adição, a parar e a voltar à intervenção. É preciso determinar quais são essas intervenções, a freqüência, a área focada; deve ser bem comportamental, deve ser bem curta, e se for longa, deve ter um limite de tempo. No nosso país, as intervenções longas não funcionam, porque não há reembolso. O que tentamos fazer é ajudar as pessoas a entender que se trata de uma doença crônica e com recaídas - tanto as pessoas que fazem as políticas quanto as pessoas que têm o problema. Não sei se respondi a questão.

RP - Entendi que um dos objetivos é educar pessoas da própria comunidade a se envolverem nas intervenções, como as mulheres Apalache, para que funcionem como agentes de saúde dentro da comunidade.

CL - Nos Estados Unidos, há um balanço entre as políticas. Existem grupos de políticas, em que tentamos mudar a política em relação à terapia para mulheres. Acreditamos que uma terapia não seja apenas terapia e entendimento, mas que terapia é também educação. Não sei se a experiência de vocês é diferente, mas é preciso um tempo para educar as pessoas e despendemos tanto tempo educando e desenvolvendo habilidades quanto gastamos para entender a dinâmica. É uma abordagem diferente. res?

$\mathrm{RP}$ - Por que o senhor acredita em mulhe-

$\mathrm{CL}$ - Por que eu acredito em mulheres? Porque tenho esposa e três filhos, duas filhas (risos). E também porque sou um homem em uma profissão de mulheres. Nos Estados Unidos, temos $10 \%$ de homens, o restante é de profissionais mulheres. Fui treinado por uma mulher, minha supervisora foi durante anos uma mulher, e meu primeiro trabalho no serviço de para mulheres. Entendi, desde então, que as mulheres que vinham ao tratamento tinham muitos problemas, mais do que os homens.

RP - Tendo em vista essas mulheres e seus filhos: aqui no Brasil temos muitas famílias em que as mulheres são as chefas de família. Os resultados nesses casos seriam melhores?

$\mathrm{CL}$ - Os resultados são ótimos. Uma das coisas que aprendemos é que, ao falar com as mulheres, é melhor falar sobre as crianças. Mesmo para alguém como eu, um homem mais velho, se falo com uma mulher sobre seus fiIhos, o contato é quase imediato. Você tem razão.

RP - Vocês estão fazendo algumas parcerias com centros de estudo em alguns países, como aqui no Brasil. Pode falar um pouco sobre isso?

$C L$ - Creio que as parcerias são um jeito incrível de aprender sobre as semelhanças. Tantas coisas são culturalmente diferentes, mas outras tantas são semelhantes. Provavelmente os comportamentos que estamos focando. O que eu aprendi aqui, sobre o compromisso dos profissionais daqui, faz com que me sinta bem. Poder vir aqui e conversar com vocês, e ver que todos temos esse objetivo de ajudar as pessoas a mudarem, o que é estimulante, e poder aprender com vocês o que nós poderíamos usar no nosso meio. Como é importante, em certas áreas e certos ambientes, que se interaja com as pessoas, não apenas intelectualmente, mas também culturalmente. É muito estimulante.

Tradução: Antônio Carlos Marques da Rosa Colaboração: Jair Knijnik - Psiquiatra; Elisabeth Meyer - Mestre em Psiquiatria; Jane L.W. Chachamovich - Assistente Social, Terapeuta de casais e família.

Endereço para correspondência:

Carl Leukefeld - Professor

Department of Behavioral Science

Center on Drug and Alcohol Research

University of Kentucky

643 Maxwelton Court, Room 103

Lexington, KY 40506-0350

859 257-2355 Telephone

859 323-1193 Fax

Web Address: http://www.uky.edu/RGS/CDAR

Copyright (c) Revista de Psiquiatria do Rio Grande do Sul - SPRS 